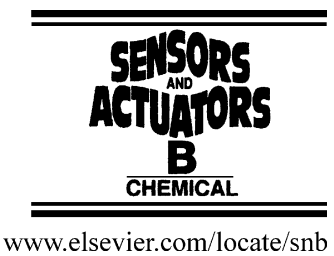

\title{
Thionine immobilized in crosslinked chitosan films
}

\author{
Leandro Gerbino ${ }^{\mathrm{a}}$, Julieta Riva ${ }^{\mathrm{b}}$, Miriam Strumia ${ }^{\mathrm{a}}$, \\ Rodrigo A. Iglesias ${ }^{b}$, , Ana M. Baruzzi ${ }^{\text {b }}$ \\ a Departamento de Química Orgánica, Facultad de Ciencias Químicas, Universidad Nacional de Córdoba, Haya de la Torre \\ esq, Medina Allende, Ciudad Universitaria, Córdoba 5000, Argentina \\ ${ }^{\mathrm{b}}$ Departamento de Fisicoquímica, Facultad de Ciencias Químicas, Universidad Nacional de Córdoba, INFIQC, CONICET, \\ Pabellón Argentina Ala 1 Piso 2, Ciudad Universitaria, Córdoba 5000, Argentina
}

Received 22 August 2007; received in revised form 21 November 2007; accepted 5 December 2007

Available online 14 December 2007

\begin{abstract}
Redox and acid-base properties of thionine immobilized in crosslinked chitosan films are analyzed. The experimental conditions for the preparation of the films are described. Results obtained with cyclic voltammetry, spectroelectrochemistry and spectrophotometry indicate that the immobilized dye retains the redox and acid-base activity of free thionine. An acid dissociation constant $\left(K_{\mathrm{a}}\right)$ for the immobilized dye of $K_{\mathrm{a}}=2.7 \times 10^{-11}$ was obtained.

Due to the stable and reversible $\mathrm{pH}$ dependent optical signal of the studied film, this membrane can be used as a building component of an optical $\mathrm{pH}$ sensor.
\end{abstract}

(C) 2007 Elsevier B.V. All rights reserved.

Keywords: Optical sensor; Electrochromism; Thin solid film; pH sensor

\section{Introduction}

Optical sensors for different analytical purposes have been extensively developed during the last decades [1-4]. They have shown advantages over other type of chemical sensors mainly due to their easy and low cost manufacturing processes, enhanced selectivity and low detection limits [5]. Usually, one or more specific indicator dyes [6-10] are immobilized into a substrate matrix, such as a polymeric film, with good filmogenic properties, mechanical stability and high diffusion rate for the analyte. Perhaps, the most trick task is to obtain the effective immobilization of the dyes in such a way that their sensing capabilities remain unaltered or even enhanced. Immobilization techniques involve mechanical entrapment [11,12], multilayered films [13], electrostatic interactions [14] and covalent immobilization [15-17]. Physical entrapment and multilayered films suffers the problem of slow leakage of the dye to the solution, while electrostatic interactions are normally efficient to immobilize a charged species but if its charge changes, diffu-

\footnotetext{
* Corresponding author. Tel.: +54 3514334169 ; fax: +54 3514334188 .

E-mail address: riglesias@mail.fcq.unc.edu.ar (R.A. Iglesias).
}

sion away from the sensing film can occur. By far, covalent immobilization is the best approach to stabilize a dye molecule inside the substrate matrix; however, in this case the optical sensitivity of the dye generally decreases. Different approaches to covalent immobilization can be found in the literature [5]; for instance, Tan et al. [15] have reported the immobilization of 1 -aminopyrene on the surface of a quartz glass functionalized with gold nanoparticles; Hashemi and Abolghasemi [16] succeeded with the immobilization of Congo Red into an agarose membrane through crosslinking with different agents.

The substrate for dye immobilization is normally a hydrophobic membrane, but in such case the ion mobility inside the polymeric matrix is normally slow, affecting the response time of the optode. The use of polyelectrolytes or ion conducting polymers has gained importance due to their excellent mechanical properties, selective diffusion of ions and bio-compatibility. Specifically, chitosan matrices have been frequently used with sensing purposes [11,18-20].

In previous reports we have characterized the redox and acid-base properties of thionine in solution [21,22]. It is very well known from the literature that this dye shows reversible redox transformation accompanied by change of coloration between two states, blue in its oxidized form and non-colored in 
its reduced state [23]. On the other side we have previously found that this dye also shows acid-base activity between two different forms, the blue-colored protonated form and a red-colored imine conjugated base [22].

In this work the immobilization of thionine into a crosslinked chitosan bed is reported. The aim of this paper is to immobilize thionine into a crosslinked chitosan film and analyze the redox and acid-base behavior of the immobilized dye. Cyclic voltammetry, spectroelectrochemistry and spectrophotometry were used for the analysis.

\section{Experimental}

\subsection{Materials}

Chitosan of low molecular weight from the shrimp shell with a degree of deacetylation of $83.3 \%$ and thionine acetate were obtained from Sigma-Aldrich. Acetic acid and glutaraldehyde $25 \%$ were obtained from J.T. Baker. Hexaammineruthenium(III) chloride, $\mathrm{Ru}\left(\mathrm{NH}_{3}\right)_{6} \mathrm{Cl}_{3}, 99 \%$, was purchased to Strem Chemicals. All chemicals were of analytical grade and used without further purification; and the solutions were prepared with ultrapure water (Milli Q-Milli RO system).

\subsection{Instrumentation}

Electrochemical and spectroelectrochemical measurements were alternatively performed using an AUTOLAB electrochemical multipurpose module with PGSTA30 or a Hi-TEK instruments potentiostat with a LYP Argentina potential generator. The cell for the spectroelectrochemical experiments was built with polytetrafluorethylene having a flat glass window on the bottom in order to reach a total internal reflection of a collimated beam arising from a $150 \mathrm{~W}$ Xe lamp bulb. The reflected light beam was collected with an Ocean Optics HR2000 spectrometer (2048 diode elements for 350-800 nm wavelength range).

A gold foil was used as counterelectrode and the interface defined by $\mathrm{Ag}|\mathrm{AgCl}|\left[\mathrm{Cl}^{-}\right]=3 \mathrm{M}$ was used as the reference electrode. All potentials are referred to this interface.

Absorption spectroscopy of thin films was performed with an UV 1601 Shimadzu spectrometer using a homemade flow cell with glass windows. Flow rate through this cell was controlled with a Gilson Minipulse 3 peristaltic pump.

\subsection{Preparation of crosslinked chitosan film}

Crosslinked chitosan membranes were prepared using glutaraldehyde as the crosslinking agent according with the following procedure. Chitosan of low molecular weight was used to prepare a $2 \% \mathrm{w} / \mathrm{v}$ solution using acetic acid solution $(2 \% \mathrm{v} / \mathrm{v})$ with vigorous stirring during $48 \mathrm{~h}$. After dissolution of the chitosan powder the solution was filtered and preserved in a colored flask. A volume of $2.50 \mathrm{~mL}$ of this solution was poured to $160 \mu \mathrm{L}$ of glutaraldehyde solution $(10 \% \mathrm{v} / \mathrm{v}$ in water) and acetic acid solution ( $2 \% \mathrm{v} / \mathrm{v})$ was added to obtain a $6 \mathrm{~mL}$ of total volume of reaction mixture. Immediately, $15 \mu \mathrm{L}$ of this final mixture were drop casted onto a polycrystalline gold electrode $\left(0.124 \mathrm{~cm}^{2}\right)$ and left to react during $48 \mathrm{~h}$ at room temperature, in an almost water saturated chamber. After solvent evaporation, a stable and homogeneous crosslinked chitosan film (CHI|GDI) was formed and washed with ultrapure water.

\subsection{Preparation of crosslinked chitosan film containing thionine dye}

Dye-containing films were prepared following the same previous sequence except that $100 \mu \mathrm{L}$ of $0.01 \mathrm{M}$ thionine solution were added to the reaction mixture before the acetic acid. In the same way, $15 \mu \mathrm{L}$ of this final mixture were poured onto the disc gold electrode and left during $48 \mathrm{~h}$ until solvent evaporation. After washing the film, the water used did not show any absorbance at $600 \mathrm{~nm}$.

\section{Results and discussion}

\subsection{Redox activity}

Fig. 1 shows the voltammogram of the heterogeneous electron transfer of $\mathrm{Ru}\left(\mathrm{NH}_{3}\right)_{6}^{3+}$, dissolved in the aqueous phase, at two different surfaces: the bare gold electrode and the film modified gold electrode. A four times lower current is observed for the process occurring through the chitosan film indicating a reduction of the diffusion coefficient of $\mathrm{Ru}\left(\mathrm{NH}_{3}\right)_{6}^{3+}$ inside the polymer layer $\left(D_{\mathrm{Ru}}^{\mathrm{film}}\right)$ and/or a reduction of the active interfacial area of the gold electrode due to blocking by the electroinactive chitosan layer. Either, as the shape and peak potential difference value is the same in both voltammograms, the diffusion or blocking effects do not influence the reversibility of the electron transfer. This last evidence is also attained by the linear relationships observed in Fig. 2, where the peak current value is plotted as a function of the square root of the sweep potential rate, for the reduction of $\mathrm{Ru}\left(\mathrm{NH}_{3}\right)_{6}^{3+}$, at the bare and film modified electrode. These linear dependences indicate that in

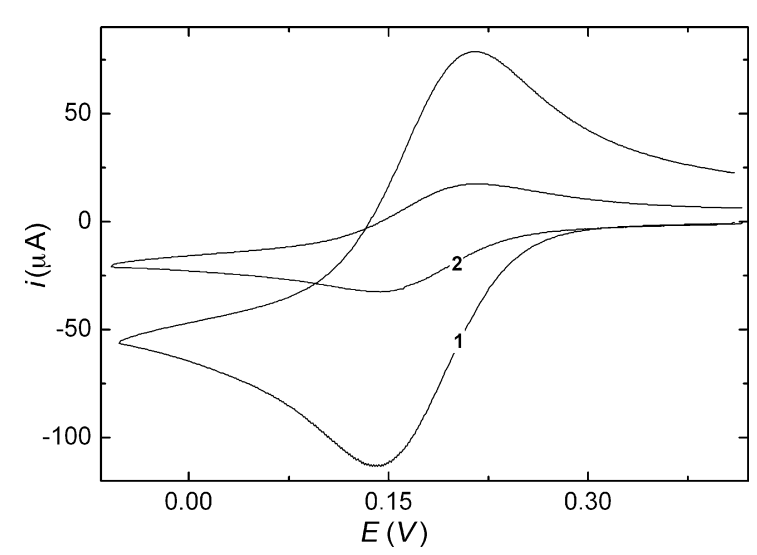

Fig. 1. Current-potential profiles corresponding to the heterogeneous transfer of $5.0 \mathrm{mM} \mathrm{Ru}\left(\mathrm{NH}_{3}\right)_{6}^{3+}$ in phosphate buffer $\left(C_{\mathrm{A}}=0.50 \mathrm{M}, \mathrm{pH} 3.0\right) . v=$ $0.100 \mathrm{~V} \mathrm{~s}^{-1}$. (1) Bare gold electrode. (2) Electrode modified with crosslinked chitosan film. 


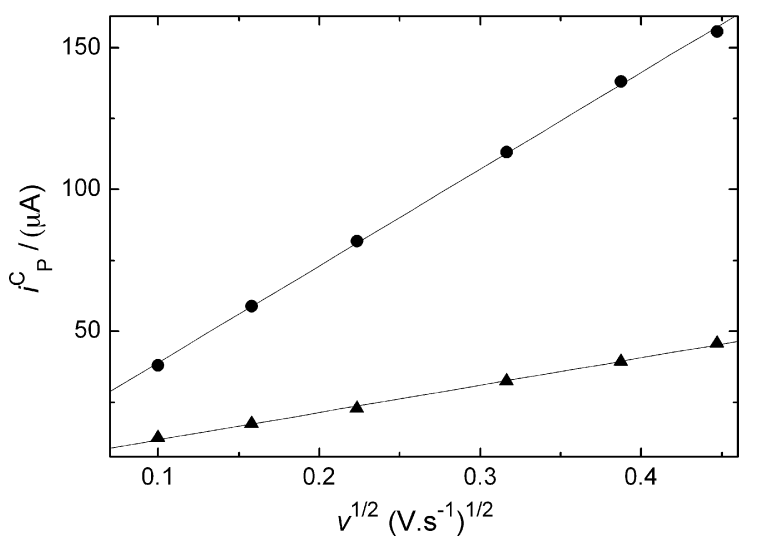

Fig. 2. Cathodic peak current dependence of the square root of sweep potential rate for the transfer of $5.0 \mathrm{mM} \mathrm{Ru}\left(\mathrm{NH}_{3}\right)_{6}^{3+}$ in phosphate buffer $\left(C_{\mathrm{A}}=0.50 \mathrm{M}, \mathrm{pH}\right.$

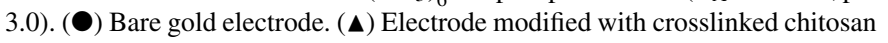
film.

both cases the heterogenous charge transfer is reversible and controlled by diffusion of the electroactive species. Linear fit of these dependences allows the determination of the diffusion coefficient of $\mathrm{Ru}\left(\mathrm{NH}_{3}\right)_{6}^{3+}$ in solution $\left(D_{\mathrm{Ru}}^{\text {sol }}\right)$. Considering that the disc gold electrode has an area $A_{\mathrm{g}}=0.108 \mathrm{~cm}^{2}$ and one of the slope gives a value of $A_{\mathrm{g}}\left(D_{\mathrm{Ru}}^{\mathrm{sol}}\right)^{1 / 2}=2.51 \times 10^{-4} \mathrm{M}$, the obtained value for the diffusion coefficient is $D_{\mathrm{E}}^{\text {sol }}=5.40 \times$ $10^{-6} \mathrm{~cm}^{2} \mathrm{~s}^{-1}$. On the other hand, as both, the active gold surface area after thin film coverage of the electrode $\left(A_{\text {eff }}\right)$ and the diffusion coefficient of $\mathrm{Ru}\left(\mathrm{NH}_{3}\right)_{6}^{3+}$ inside the film $\left(D_{\mathrm{Ru}}^{\mathrm{film}}\right)$ are unknown, the other slope allows only the quantification of $A_{\text {eff }}\left(D_{\mathrm{RH}}^{\mathrm{film}}\right)^{1 / 2}=7.06 \times 10^{-5} \mathrm{M}$. However, considering the value of $D_{\mathrm{Ru}}^{\mathrm{tilm}}<5 \times 10^{-7} \mathrm{~cm}^{2} \mathrm{~s}^{-1}$ reported in the literature for crosslinked chitosan films [24], the main effect of the change in the diffusion control across the chitosan film must be given by a pronounced reduction of the diffusion coefficient value of $\mathrm{Ru}\left(\mathrm{NH}_{3}\right)_{6}^{3+}$ instead of a blocking effect due to the electroinactive layer (i.e. $D_{\mathrm{Ru}}^{\text {film }}<D_{\mathrm{Ru}}^{\text {sol }}$ and $A_{\mathrm{eff}} \cong A_{\mathrm{g}}$ ).

Fig. 3A shows the voltammograms corresponding to the heterogeneous charge transfer of $\mathrm{Ru}\left(\mathrm{NH}_{3}\right)_{6}^{3+}$ at a chitosan film modified electrode and at an electrode with a film containing thionine (THI) immobilized in the crosslinked chitosan matrix. The decrease of the backward (anodic) peak corresponding to the dye-containing film is the main aspect that should be observed. This fact becomes more evident when the sweep potential rate becomes smaller as indicated in Fig. 3B where the charge difference $(\Delta Q)$ denoted in Fig. 3A is plotted against the reciprocal of the square root of the sweep potential rate. Smaller is the sweep potential rate higher is the charge difference. This evidence is typical of EC reactions and in this case implies that $\mathrm{Ru}\left(\mathrm{NH}_{3}\right)_{6}^{3+}$, formed during the cathodic scan, is consumed by a coupled chemical reaction and it is not available to be reoxidized during the anodic scan. Particularly, immobilized THI is the only species capable to react with the metal complex; i.e. $\mathrm{Ru}\left(\mathrm{NH}_{3}\right)_{6}^{3+}$ is reduced at the surface of the metal electrode to $\mathrm{Ru}\left(\mathrm{NH}_{3}\right)_{6}^{3+}$ and this species can react through a redox irreversible reaction with THI to produce $\mathrm{Ru}\left(\mathrm{NH}_{3}\right)_{6}^{3+}$ and the reduced form of the dye, leucothionine [25-27], which, due to its lower charge delocalization (see reaction (R.2)), is a non-visible absorbing species. Additional evidence to support this mechanism is given in Fig. 4 where the in situ interfacial absorbance spectrum of the film is recorded during a cyclic voltammetric experiment. $\mathrm{As} \mathrm{Ru}\left(\mathrm{NH}_{3}\right)_{6}^{3+}$ is formed during the cathodic scan, the in situ interfacial absorbance spectrum shows one negative band centered at $650 \mathrm{~nm}$ which corresponds to the absorption spectrum of THI included in a crosslinked chitosan matrix (see inset of Fig. 4). This negative band indicates the decrease of THI inside the thin film followed by the formation of leucothionine without visible absorption. In this way, considering the reduction of THI
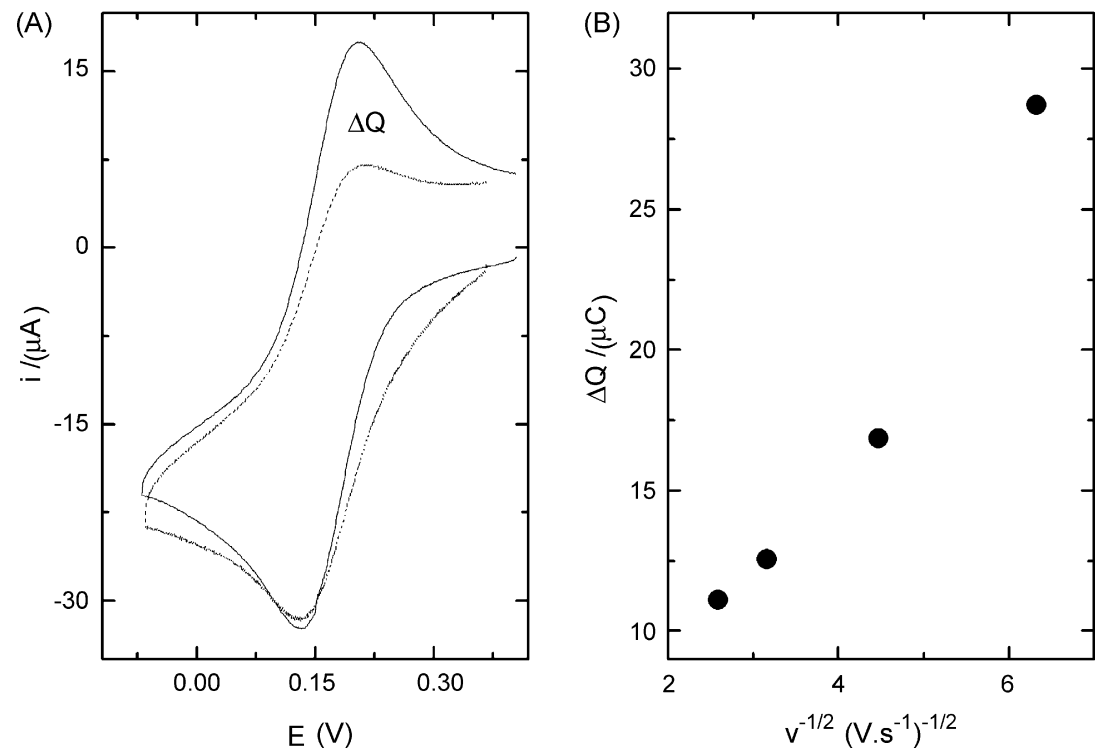

Fig. 3. (A) Current-potential profiles corresponding to the heterogeneous transfer of $5.0 \mathrm{mM} \mathrm{Ru}\left(\mathrm{NH}_{3}\right)_{6}^{3+}$ in phosphate buffer $\left(C_{\mathrm{A}}=0.50 \mathrm{M}, \mathrm{pH} 3.0\right) \cdot v=0.010 \mathrm{~V} \mathrm{~s}{ }^{-1}$. (-) Electrode modified with crosslinked chitosan film. (-) Electrode modified with crosslinked chitosan film containing THI. (B) Graph of difference in the charge transference values between both modified electrodes measurements vs. square root of the sweep potential rate. 


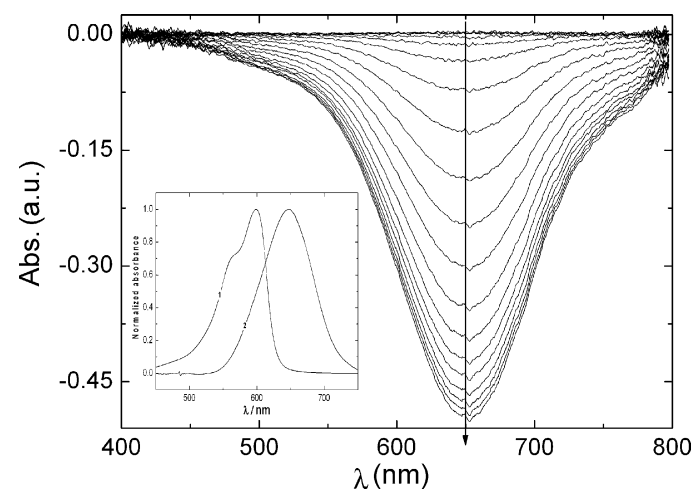

Fig. 4. Interfacial absorbance spectra of THI|CHI|GDI obtained during the electrochemical reduction of $5 \mathrm{mM}$ of $\mathrm{Ru}\left(\mathrm{NH}_{3}\right)_{6}^{3+}$ in phosphate buffer $(\mathrm{pH} 3.17$, $\left.C_{\mathrm{A}}=0.10 \mathrm{M}\right) \cdot v=0.010 \mathrm{~V} \mathrm{~s}^{-1} \cdot E_{\text {initial }}=0.40 \mathrm{~V} ; E_{\text {final }}=-0.05 \mathrm{~V}$. Inset: normalized spectra. (1) Thionine in aqueous solution and (2) thionine in crosslinked chitosan.

to leucothionine, the proposed global mechanism is:

$\mathrm{Ru}\left(\mathrm{NH}_{3}\right)_{6}^{3+}+1 \mathrm{e}^{-} \rightleftarrows \mathrm{Ru}\left(\mathrm{NH}_{3}\right)_{6}^{2+}$

$\mathrm{Thio}_{(\text {film })}^{+}+\mathrm{H}^{+}+2 \mathrm{Ru}\left(\mathrm{NH}_{3}\right)_{6}^{2+} \rightarrow \mathrm{HThio}_{(\text {film })}+2 \mathrm{Ru}\left(\mathrm{NH}_{3}\right)_{6}^{3+}$

It should be noticed that the diffusion rate of $\mathrm{Ru}\left(\mathrm{NH}_{3}\right)_{6}^{3+}$ away from the electrode surface and into the polymer layer determines the time response of the optical signal; however, the non-linearity of the plot shown in Fig. 3B is a clear indication that not only the diffusion but also the kinetic of the coupled chemical reaction (R.2) have to be considered.

It is well know that leucothionine can be reversible oxidized to the THI form [25-27], however, in this case the reverse of reaction (R.2) is thermodynamically unfavorable and leucothio-

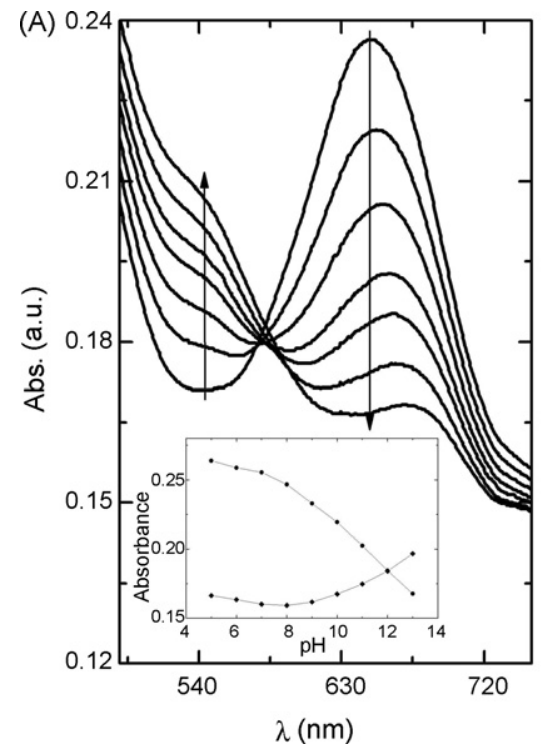

nine can be fully reoxidized if the film is left in contact with an oxygen saturated electrolyte. In this case repeated voltammograms obtained after this treatment do not show any differences (not shown in figures).

\subsection{Acid-base activity}

In a previous work [21] we analyzed the acid-base equilibrium of THI in aqueous solutions and found that at high $\mathrm{pH}$ values $(\mathrm{pH}>10)$ a conjugated imine base is reversibly formed:<smiles></smiles>

This acid-base equilibrium is followed by a noticeable change in the absorption spectrum because THI has an absorption maximum located at $650 \mathrm{~nm}$ while the imine absorbs mainly at $540 \mathrm{~nm}$.

When THI is immobilized into a CHI|GDI film, the same equilibrium occurs as it is shown in Fig. 5A. In this figure the absorbance spectra of a THI|CHI|GDI film are plotted for different $\mathrm{pH}$ values. At $\mathrm{pH}<9$ and $\mathrm{pH}>12.5$ approximately constant spectra are obtained. Considering that the spectrum at $\mathrm{pH} 9.3$ is due to the THI form while the spectrum at $\mathrm{pH} 12.4$ accounts only for the imine form, the acid dissociation constant of THI immobilized in the THI|CHIGDI film can be obtained using the slope of the parametric plot shown in Fig. 5B (see Appendix for details). In this figure the absorbance at a given $\mathrm{pH}$ value divided by that at $\mathrm{pH} 9.3$ is plotted against the absorbance at $\mathrm{pH}$ 12.4 divided that at $\mathrm{pH} 9.3$; this is done in a wavelength range given by $540 \mathrm{~nm}<\lambda<660 \mathrm{~nm}$ (spectra overlapping). The acid dissociation constant obtained in this way is $K_{\mathrm{a}}=2.7 \times 10^{-11}$ $\left(\mathrm{p} K_{\mathrm{a}}=10.6\right)$.

It can be noted that the changes of absorbance with $\mathrm{pH}$ show a linear relationship for $\mathrm{pH}$ values ranging from 9 to at least

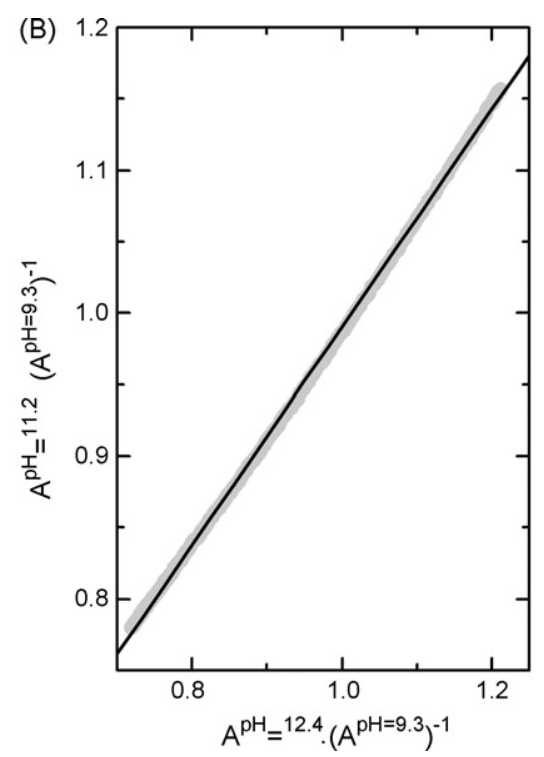

Fig. 5. (A) Absorbance spectra of the THI|CHI|GDI film obtained at different pH values. Inset: absorbance changes as a function of solution pH taken at the peak wavelengths: (--) $\lambda=647 \mathrm{~nm} ;(--) \lambda=540 \mathrm{~nm}$. (B) Linearization of absorbance ratios (see Appendix) to obtain the acid dissociation constant corresponding to the immobilized dye. pH 11.2. (一) Linear fit. (־) Experimental data. 


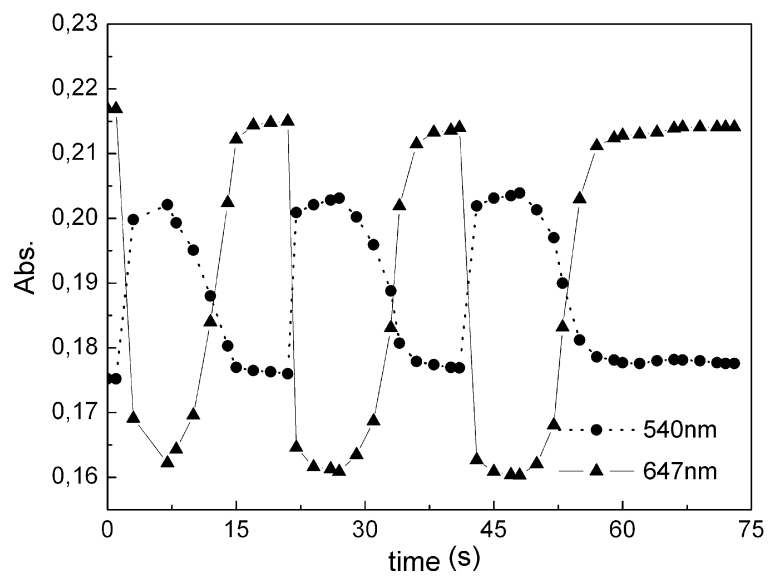

Fig. 6. Absorbance of THI|CHI|GDI taken at $540 \mathrm{~nm}(\boldsymbol{O})$ and $647 \mathrm{~nm}(\boldsymbol{\Delta})$ during successive changes of $\mathrm{pH}$ between $\mathrm{pH} 9.3$ and $\mathrm{pH} 12.4$

13 units (see inset of Fig. 5a). For $\mathrm{pH}<7$ the optical signal remains constant indicating that an optical sensor build with this membrane is useful for high $\mathrm{pH}$ values were a $\mathrm{pH}$ glass electrode suffers of alkaline errors.

Reversibility and time response of the optical signal of $\mathrm{THI}|\mathrm{CHI}| \mathrm{GDI}$ films under $\mathrm{pH}$ variations are important aspects to be considered. The absorbencies at 540 and $645 \mathrm{~nm}$ are followed as the film is alternatively put in contact with buffer solutions of pH 9.3 and $\mathrm{pH} 12.4$, respectively. Fig. 6 shows that the stationary optical signal is reversible after several cycles. It is important to remark that the time responses are considerable shorter than for other optical $\mathrm{pH}$-sensitive films reported in the literature [28-31]. It takes less than $5 \mathrm{~s}$ to reach a stationary optical signal when the $\mathrm{pH}$ increases while $15 \mathrm{~s}$ are needed when the $\mathrm{pH}$ decreases. This difference of the response time would be given by different diffusion coefficients of $\mathrm{H}^{+}$and $\mathrm{HO}^{-}$inside the polymer layer due to some kind of electrostatic interaction with the positive charge density of the CHI|GDI film. Gorski and coworkers [24] have reported similar aspects when they studied the voltammetric response of anionic and cationic redox species at chitosan film modified electrodes.

Fig. 7 shows the change of the in situ absorbance spectrum of a THI|CHI|GDI film modified electrode when $\mathrm{H}_{2} \mathrm{O}_{2}$ is reduced

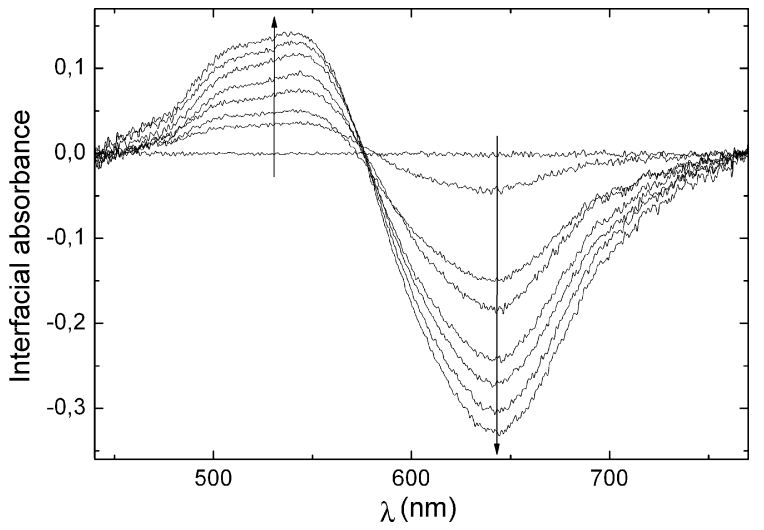

Fig. 7. Interfacial absorbance spectra of $\mathrm{THI}|\mathrm{CHI}| \mathrm{GDI}$ obtained during the electrochemical reduction of $\mathrm{H}_{2} \mathrm{O}_{2}$ at $0.0 \mathrm{~V}$ (vs. $\mathrm{Ag} / \mathrm{AgCl} / \mathrm{KCl}$ sat.). Reference spectrum at open circuit. by a cathodic step potential applied at the electrode. When $\mathrm{H}_{2} \mathrm{O}_{2}$ is reduced at the gold surface the following global heterogeneous transfer takes place:

$\mathrm{H}_{2} \mathrm{O}_{2(\mathrm{aq})}+\mathrm{H}_{(\mathrm{aq})}^{+}+2 e \rightleftarrows \mathrm{H}_{2} \mathrm{O}_{(\mathrm{l})}+\mathrm{HO}_{(\mathrm{aq})}^{-}$

This interfacial reaction provokes a local $\mathrm{pH}$ change due to the formation of $\mathrm{HO}^{-}$which changes the acid-base equilibrium of THI. Concomitant with the $\mathrm{HO}^{-}$formation, $\mathrm{THI}$ is progressively transformed to the imine form with the corresponding diminution of the absorbance at $650 \mathrm{~nm}$ and the increase at $540 \mathrm{~nm}$. This result indicates the utility of the $\mathrm{THI}|\mathrm{CHI}| \mathrm{GDI}$ film modified electrode as an optical $\mathrm{pH}$-sensitive membrane.

\section{Conclusion}

Thionine was effectively immobilized inside the crosslinked chitosan matrix and this composite showed excellent filmogenic properties. This dye is irreversibly bounded to the polymer and its stability, after physical and chemical changes, indicates that it is probably covalently bounded to the crosslinked chitosan matrix. We are studying at the moment the interaction between thionine and the polymer matrix.

It is known that the amino groups play an important role when THI is reduced or deprotonated in solution due to delocalization of charge onto this site; noteworthy, when the dye is immobilized inside the polymer matrix, almost the same chemical properties are observed; indicating that at least one of the amino groups remains free to react, i.e. the dye should be located as pendant groups of the polymer matrix. Particularly, this is necessary for the formation of the conjugated imine base of thionine.

The global mechanism involved during the reduction of $\mathrm{Ru}\left(\mathrm{NH}_{3}\right)_{6}^{3+}$ at the dye-containing film modified electrode has been characterized. It was shown that not only diffusion control but also the kinetic of the coupled chemical reaction determine the rate of reduction of the dye. Numerical simulations of the global process considering diffusion in solution and diffusion across a thin polymer film, and kinetics for an EC reaction are currently being performed. Work is being carried out related to this latter aspect.

Immobilized thionine cannot be reduced by applying cathodic potential values to the electrode, but as the dye retains its redox activity, perhaps a conducting copolymer inserted in the matrix must allow for the electrochemical reduction-oxidation of the immobilized dye. If this is the case, these films can be directly used as a component of smart windows.

In this paper, the acid dissociation constant of the immobilized dye was also determined. The $\mathrm{pH}$ dependent absorbance of the THI|CHI|GDI film, its reversibility and short response time makes this thin film membrane a good candidate for the construction of a miniaturized optical $\mathrm{pH}$ sensor.

\section{Acknowledgements}

L.G. thank CONICET for the fellowship granted. J.R. thank Secretaría de Extensión Universitaria (SEU-UNC) for the fellowship granted. R.A.I., M.S. and A.M.B. are career members of 
Consejo Nacional de Investigaciones Científicas y Tecnológicas (CONICET). Financial support from CONICET, SEU-UNC and Secretaría de Ciencia y Tecnología (SECyT-UNC) are gratefully acknowledged.

\section{Appendix A}

Considering a thin film containing two immobilized species related by an acid base reaction with an acid dissociation constant $K_{\mathrm{a}}$ :

$\mathrm{HT}_{\text {(film) }}^{+}+\mathrm{HO}_{(\mathrm{aq})}^{-} \rightleftarrows \mathrm{T}_{(\text {film })}+\mathrm{H}_{2} \mathrm{O}_{(\mathrm{l})}$

For the particular case treated in this work $\mathrm{HT}^{+}$is thionine while $\mathrm{T}$ is its conjugated imine base.

The total absorbance of the film $(A(\lambda, \mathrm{pH}))$ will depend on wavelength $(\lambda)$ and $\mathrm{pH}$ of the surrounding solution; and it can be written as the sum of the individual absorbencies corresponding to $\mathrm{HT}^{+}$and $\mathrm{T}$ :

$A(\lambda, \mathrm{pH})=A_{\mathrm{HT}}(\lambda, \mathrm{pH})+A_{\mathrm{T}}(\lambda, \mathrm{pH})$

and using the Beer-Lambert's law:

$A(\lambda, \mathrm{pH})=\varepsilon_{\mathrm{HT}}^{\lambda} \gamma\left[\mathrm{HT}^{+}\right]+\varepsilon_{\mathrm{T}}^{\lambda} \gamma[\mathrm{T}]$

being $\varepsilon_{\mathrm{HT}}^{\lambda}, \varepsilon_{\mathrm{T}}^{\lambda}$ the molar absorptivities of $\mathrm{HT}^{+}$and $\mathrm{T}$, respectively; $\gamma$ the optical path length through the film (normally the film thickness); and $\left[\mathrm{HT}^{+}\right],[\mathrm{T}]$ the film concentration of $\mathrm{HT}^{+}$ and $\mathrm{T}$, respectively.

At sufficiently high $\mathrm{pH}$ values $\left(\mathrm{pH}_{\mathrm{I}}\right)$ the only one absorbing species is $\mathrm{T}$ while $\mathrm{HT}^{+}$is responsible for the total absorbance at very low $\mathrm{pH}$ values $\left(\mathrm{pH}_{\mathrm{II}}\right)$; i.e.:

High $\mathrm{pH}$ values $\left(\mathrm{pH}_{\mathrm{I}}>\mathrm{p} K_{\mathrm{a}}+2\right)$ :

$A\left(\lambda, \mathrm{pH}_{\mathrm{I}}\right)=A_{\mathrm{T}}\left(\lambda, \mathrm{pH}_{\mathrm{I}}\right)=\varepsilon_{\mathrm{T}}^{\lambda} \gamma C_{\mathrm{A}}$

Low $\mathrm{pH}$ values $\left(\mathrm{pH}_{\mathrm{II}}<\mathrm{p} K_{\mathrm{a}}-2\right)$ :

$A\left(\lambda, \mathrm{pH}_{\mathrm{II}}\right)=A_{\mathrm{HT}}\left(\lambda, \mathrm{pH}_{\mathrm{II}}\right)=\varepsilon_{\mathrm{HT}}^{\lambda} \gamma C_{\mathrm{A}}$

being $C_{\mathrm{A}}=\left[\mathrm{HT}^{+}\right]+[\mathrm{T}]$ the total analytical concentration.

By taking off the molar absorptivities from Eq. (A.3) and (A.4) and replacing them into Eq. (A.2) the following expression can be obtained:

$\frac{A(\lambda, \mathrm{pH})}{A_{\mathrm{T}}\left(\lambda, \mathrm{pH}_{\mathrm{I}}\right)}=\frac{A_{\mathrm{HT}}\left(\lambda, \mathrm{pH}_{\mathrm{II}}\right)}{A_{\mathrm{T}}\left(\lambda, \mathrm{pH}_{\mathrm{I}}\right)} \frac{\left[\mathrm{HT}^{+}\right]}{C_{\mathrm{A}}}+\frac{[\mathrm{T}]}{C_{\mathrm{A}}}$

Thus, a parametric plot of $A(\lambda, \mathrm{pH}) / A_{\mathrm{T}}\left(\lambda, \mathrm{pH}_{\mathrm{I}}\right)$ as a function of $A_{\mathrm{HT}}\left(\lambda, \mathrm{pH}_{\mathrm{II}}\right) / A_{\mathrm{T}}\left(\lambda, \mathrm{pH}_{\mathrm{I}}\right)$ gives a straight line with slope $a=\left[\mathrm{HT}^{+}\right] / C_{\mathrm{A}}$ and $y$-intercept $b=[\mathrm{T}] / C_{\mathrm{A}}$.

Finally, the acid dissociation constant can be computed by:

$K_{\mathrm{a}}=\frac{b}{a}\left[H^{+}\right]$

Main advantages of this methodology are that the spectra for $\mathrm{HT}^{+}$and $\mathrm{T}$ can be overlapped and the total species concentration $\left(C_{\mathrm{A}}\right)$ and film thickness $(\gamma)$ are not necessarily needed.

\section{References}

[1] P. Bühlmann, E. Pretsch, E. Bakker, Carrier-based ion-selective electrodes and bulk optodes. 2. Ionophores for potentiometric and optical sensors, Chem. Rev. 98 (1998) 1593-1687.

[2] I. Sánchez-Barragán, J.M. Costa-Fernández, A. Sanz-Medel, Tailoring the $\mathrm{pH}$ response range of fluorescent-based $\mathrm{pH}$ sensing phases by sol-gel surfactants co-immobilization, Sens. Actuator B Chem. 107 (2005) 6976.

[3] K.P. Dobmeier, G.W. Charville, M.H. Schoenfisch, Nitric oxide-releasing xerogel-based fiber-optic pH sensors, Anal. Chem. 78 (2006) 7461-7466.

[4] Z. Ge, C.W. Brown, L. Sun, S.C. Yan, Fiber-optic pH sensor based on evanescent wave absorption spectroscopy, Anal. Chem. 65 (1993) $2335-2338$

[5] E. Bakker, P. Bühlmann, E. Pretsch, Carrier-based ion-selective electrodes and bulk optodes. 1. General characteristics, Chem. Rev. 97 (1997) 3083-3132.

[6] M. Puyol, C. Encinas, L. Rivera, S. Miltsov, J. Alonso, Characterisation of new norcyanine dyes and their application as $\mathrm{pH}$ chromoionophores in optical sensors, Dyes and Pigments 73 (2007) 383-389.

[7] A. Safavi, M. Bagheri, Novel optical $\mathrm{pH}$ sensor for high and low $\mathrm{pH}$ values, Sens. Actuator B Chem. 90 (2003) 143-150.

[8] A. Song, S. Parus, R. Kopelman, High-performance fiber-optic $\mathrm{pH}$ microsensors for practical physiological measurements using a dualemission sensitive dye, Anal. Chem. 69 (1997) 863-867.

[9] D. Citterio, L. Jenny, S. Rásonyi, U.E. Spihiger, Dyes for use in integrated optical sensors, Sens. Actuator B Chem. 39 (1997) 202-206.

[10] O.S. Wolfbeis, Materials for fluorescence-based optical chemical sensors, J. Mater. Chem. 15 (2005) 2657-2669.

[11] T. Klotzbach, M. Watt, Y. Ansari, S.D. Minteer, Effects of hydrophobic modification of chitosan and Nafion on transport properties, ion-exchange capacities, and enzyme immobilization, J. Memb. Sci. 282 (2006) 276283.

[12] M. García-Heras, C. Gil, N. Carmona, J. Faber, K. Kromka, M.A. Villegas, Optical behaviour of $\mathrm{pH}$ detectors based on sol-gel technology, Anal. Chim. Acta 540 (2005) 147-152.

[13] Y. Egawa, R. Hayashida, J. Anzai, Multilayered assemblies composed of brilliant yellow and poly(allylamine) for an optical $\mathrm{pH}$ sensor, Anal. Sci. 22 (2006) 1117-1119.

[14] M. Chiou, P. Ho, H. Li, Adsorption of anionic dyes in acid solutions using chemically cross-linked chitosan beads, Dyes and Pigments 60 (2004) 69-84.

[15] S. Tan, Y. Hu, J. Chen, G. Shen, R. Yu, An optical sensor based on covalent immobilization of 1-aminopyrene using Au nanoparticles as bridges and carriers, Sens. Actuator B Chem. 124 (2007) 68-73.

[16] P. Hashemi, M.M. Abolghasemi, Preparation of a novel optical sensor for low $\mathrm{pH}$ values using agarose membranes as support, Sens. Actuator B Chem. 115 (2006) 49-53.

[17] Z. Rosenzweig, R. Kopelman, Analytical properties and sensor size effects of a micrometer-sized optical fiber glucose biosensor, Anal. Chem. 68 (1996) 1408-1413.

[18] Y. Wan, K.A.M. Creber, B. Peppley, V.T. Bui, Chitosan-based solid electrolyte composite membranes I. Preparation and characterization, J. Memb. Sci. 280 (2006) 666-674.

[19] M. Darder, M. Colilla, E. Ruiz-Hitzky, Chitosan-clay nanocomposites: application as electrochemical sensors, Appl. Clay Sci. 28 (2005) 199208.

[20] M. Xue, Q. Xu, M. Zhou, J. Zhu, In situ immobilization of glucose oxidase in chitosan-gold nanoparticle hybrid film on Prussian Blue modified electrode for high-sensitivity glucose detection, Electrochem. Commun. 8 (2006) 1468-1474.

[21] V.E. Nicotra, M.F. Mora, R.A. Iglesias, A.M. Baruzzi, Spectroscopic characterization of thionine species in different media, Dyes and Pigments 76 (2008) 315-318.

[22] R.A. Iglesias, M.F. Mora, A.M. Baruzzi, Spectroelectrochemical analysis of the thionine transfer coupled to a photoinduced chemical reaction across the water 1,2-dichloroethane interface, J. Electroanal. Chem. 585 (2005) 113-119. 
[23] E. Rabinowitch, The photogalvanic effect. I. The photochemical properties of the thionine-iron system, J. Chem. Phys. 8 (1940) 551-559.

[24] J. Cruz, M. Kawasaki, W. Gorski, Electrode coatings based on chitosan scaffolds, Anal. Chem. 72 (2000) 680-686.

[25] R. Yang, C.M. Ruan, W.L. Dai, J.Q. Deng, J.L. Kong, Electropolymerization of thionine in neutral aqueous media and $\mathrm{H}_{2} \mathrm{O}_{2}$ biosensor based on poly(thionine), Electrochim. Acta 44 (1999) 1585-1596.

[26] V. Ganesan, R. Ramaraj, In situ spectroelectrochemical studies of phenothiazine dyes at clay coated electrodes, J. Electroanal. Chem. 490 (2000) 54-61.

[27] K. Viswanathan, P. Natarajan, Photophysical properties of thionine and phenosafranine dyes covalently bound to macromolecules, J. Photochem. Photobiol. A Chem. 95 (1996) 245-253.

[28] P. Sotomayora, I. Raimundo Jr., A. Zarbinb, J. Rohweddera, G. Oliveira Netoc, O. Alves, Construction and evaluation of an optical $\mathrm{pH}$ sensor based on polyaniline-porous Vycor glass nanocomposite, Sens. Actuator B Chem. 74 (2001) 157-162.

[29] Y. Lee, B. Joo, N. Choi, J. Lim, J. Huh, D. Lee., Visible optical sensing of ammonia based on polyaniline film, Sens. Actuator B Chem. 93 (2003) $148-152$.

[30] A. Talaie, Conducting polymer based $\mathrm{pH}$ detector: a new outlook to $\mathrm{pH}$ sensing technology, Polymer 38 (1997) 1145-1150.

[31] Z. Jin, Y. Su, Y. Duan, Development of a polyaniline-based optical ammonia sensor, Sens. Actuator B Chem. 72 (2001) 75-79.

\section{Biographies}

Leandro Gerbino received his BSc degree in the Universidad Nacional de Córdoba, Argentina, 2004. He is now a PhD student in the Departamento de Química Orgánica, Facultad de Ciencias Químicas, Universidad Nacional de
Córdoba (FCQ-UNC). His current research interests are synthesis and characterization of polymers containing dyes and its application to the development of electrochromic devices.

Julieta Riva received her BSc degree in the Universidad Nacional de Córdoba, Argentina, 2007. She is currently developing a PhD career in the Departamento de Fisicoquímica (FCQ-UNC). Her current research interests are spectroelectrochemistry of thin polymer layer with interest in the development of optical sensors and electrochromic devices.

Miriam Strumia has received her Doctor degree in 1982 at the Universidad Nacional de Córdoba. Currently she is Professor at the Organic Chemistry Department, Facultad de Ciencias Químicas, Universidad Nacional de Córdoba and researcher of the Consejo Nacional de Investigaciones Científicas y Técnicas (CONICET). Her current research interests involve polymer synthesis and polymer chemistry.

Rodrigo Iglesias has received his Doctor in Chemistry degree in 2003 at the Facultad de Ciencias Químicas, Universidad Nacional de Córdoba. His current positions are Assistant Professor at the Facultad de Ciencias Químicas, Universidad Nacional de Córdoba and Assistant Researcher at CONICET. Nowadays he is performing research activities related to thin film modified electrodes with optical and electrochemical properties for the improvement of optical sensors, smart windows and dye sensitized solar cells.

Ana Baruzzi has received her Doctor in Chemistry degree at the Facultad de Ciencias Químicas, Universidad Nacional de Córdoba. She is Professor at the Facultad de Ciencias Químicas, Universidad Nacional de Córdoba and Researcher at CONICET. Nowadays she is performing research activities related to the improvement of different kinds of chemical and optical sensors focusing on the analytical detection of biological species. 